\title{
The Role of Extraversion and Openness on Host Country Nationals' Task Performance and Contextual Performance at Work
}

This article was published in the following Dove Press journal: Psychology Research and Behavior Management

\author{
Milad T Jannesari' \\ Zhongming Wang ${ }^{2}$ \\ Jianzhuang Zheng' \\ Wenwu Xie \\ Qin Lai ${ }^{1}$ \\ Lu Wu' \\ 'School of Business, Zhejiang University \\ City College, Hangzhou, People's \\ Republic of China; ${ }^{2}$ School of \\ Management, Zhejiang University, \\ Hangzhou, People's Republic of China
}

Purpose: This study answer calls for research on host country nationals (HCNs) by examining factors that may influence $\mathrm{HCN}$ task performance and contextual performance during work with their self-initiated expatriate (SIE) colleagues.

Participants and Methods: Data on personality traits (extraversion, openness), socialization self-efficacy, and frequency of interaction, task, and contextual performance were collected by surveying 373 Chinese HCNs. The first author recruited the HCNs through SIEs working and living in China. SIEs who participated in this project provided the email addresses of HCNs with whom they worked.

Results: The frequency of interactions fully mediated the relationship between (a) extraversion with task and contextual performance and (b) openness with task and contextual performance. Only socialization self-efficacy moderated the mediating effects of extraversion on task performance via the frequency of interaction; it also moderated the mediating effects of openness on contextual performance via the frequency of interactions, but not in the hypothesized direction.

Conclusion: This study investigated the neglected stakeholder in the expatriation process, namely, HCNs, and what factors may impact HCNs' performance during work and collaboration with their SIE colleagues.

Keywords: host country nationals, expatriates, career, personality, socialization self-efficacy

\section{Introduction}

Approximately $40 \%$ of global employers report experiencing problems in filling positions due to talent shortages, ${ }^{1}$ with many organizations increasingly using expatriates to meet their talent requirements. ${ }^{2-4,73}$ The average size of a multinational company's expatriate workforce has grown by almost $33 \%$ over the last 12 years. ${ }^{1}$ With the increased use of both corporate expatriates (CEs), defined as employees sent by a parent company to work away from their home base, ${ }^{2}$ and self-initiated expatriates (SIEs), defined as individuals who have chosen to relocate themselves in a host country, ${ }^{5}$ increasing research efforts have been made to more fully understand the relationship between international assignments and expatriate performance. ${ }^{2,6-8}$

Early research on international assignments has tended to be "expatriate-centric" (page. 1041), ' with host country nationals (HCNs) being a "neglected stakeholder" in this study (page. 2928). ${ }^{10}$ Although more recent conceptualizations and studies have explored the effect of HCNs' attitudes on their willingness to provide support
Correspondence: Milad T Jannesari School of Business, Zhejiang University City College, Hangzhou, People's Republic of China

Email miladjannesari@gmail.com 
to expatriates ${ }^{10-14}$ and how $\mathrm{HCNs}$ ' reactions to payment policies influence their interactions with expatriates and expatriate performance, ${ }^{15,16}$ relatively little is known about HCNs as actors in the expatriate-host country national (E-HCN) relationship. ${ }^{17}$ Moreover, despite the growing interest in the E-HCN relationship, the current focus is still on how this relationship may influence expatriate mobility ${ }^{18}$ and performance. ${ }^{19}$ No research has specifically examined how the E-HCN relationship may influence the performance of HCNs. The function of job performance can be represented by the amount of time, energy, and effort that individuals allocate to their job and colleagues. $^{20}$ According to Caliguri, job performance is conceptualized as a multidimensional construct consisting of more than one kind of behavior. Lee et $\mathrm{al}^{21}$ reported that in cross-cultural studies, two sub-dimensions of job performance, namely, task and contextual performance, are the most significant factors predicting the job performance of individuals during their global work experience. However, cross-cultural researchers have identified the factors that contribute to an individual's job performance. These factors are mainly related to personality differences, organizational differences, and situational differences. ${ }^{22}$ In this area of study, individual differences in personality traits are the main factor that determines job performance in cross-cultural situations. In additional, in cross-cultural situations, when foreign and local employees are working together they often encounter uncertainty about what behaviors are appropriate or acceptable for their local/foreign peers. $^{23}$ This uncertainty negatively effects their performance. $^{24}$ In this study, the "individual's personality traits serve as a substratum of one's cognitive and learning ability in a foreign culture, and will constrain one's competency to gain subsequent skills" (page. 3814). ${ }^{25}$

The purpose of this study was to build upon and extend previous research on international assignments by putting HCNs center stage and focusing on how the E-HCN frequency of interactions, which we defined as the degree to which SIEs communicate regularly and feel the obligation to build and sustain relationships, as a measure of relationship quality, may influence HCN performance. This study contributes to the research on international assignments in three major ways. First, although several studies have examined the performance of CEs and SIEs, ${ }^{3,26}$ these studies have neglected the performance of HCNs when they are working with $\mathrm{CE}$ or SIE colleagues. Even when HCNs are considered, they are done so as a secondary factor in relation to the outcomes of CEs or SIEs. ${ }^{27}$ Any relationship requires two actors, yet research on international assignments has failed to consider how $\mathrm{HCN}$ interactions with CEs or SIEs may affect his/her performance. This study therefore answers calls for more research on HCNs in this context. ${ }^{10,16}$

Second, this study extends previous research by examining the nature of the E-HCN frequency of interactions, and whether this factor mediates the association between the HCNs' personality and performance. Previous research has examined how expatriates experience stress due to their status as newcomers to the work environment, and how that stress influences their performance. 9 However, previous work has not considered that the HCNs who work closely with an expatriate may also experience uncertainty and stress. Given that HCNs and expatriates are often from different cultural backgrounds, HCNs must learn to navigate these differences while maintaining their productivity. ${ }^{28}$ Drawing from social capital theory, ${ }^{29,30}$ this study examines how the relationship between an expatriate and an HCN may facilitate the HCN's performance. Social capital is defined as "the sum of actual and potential resources embedded within, available through, and derived from the network of relationships possessed by an individual or social unit" (page. 243). ${ }^{31}$ According to social capital theory, organizations are social communities in which relationships between actors are enacted. ${ }^{31,32}$ Through interactions, actors share information and provide emotional support to one another. ${ }^{33}$ The relationships between actors form the basis for trust, shared meaning, and cooperation so that goals can be achieved. ${ }^{31}$ For example, a growing body of research has examined the positive association between the attainment and use of social capital and positive career outcomes including higher salaries, promotions, and career satisfaction. ${ }^{34}$ Drawing from social capital theory, ${ }^{29,31}$ we delineated the E-HCN frequency of interactions that may mediate the association between HCNs' personality and performance.

Third, while previous studies have examined the socialization self-efficacy of expatriates, no research has yet considered how interactions with expatriates may change the HCNs' perceptions and behaviors to suit the new rules, roles, and norms of foreigner groups and style of work within multinational organizational environments. Socialization self-efficacy was defined as a tactic that can help individuals cope with new experiences, such as engaging with colleagues from different cultural backgrounds. ${ }^{21}$ Considering that personality traits are considered to be relatively stable, ${ }^{35}$ it is 
important to determine whether changes in perceptions and behaviors due to socialization self-efficacy can enhance the $\mathrm{HCN}$-expatriate frequency of interactions and performance, even in HCNs with extraversion and openness personality traits. By studying whether socialization self-efficacy moderates the mediation effect between HCN personality and performance via the E-HCN relationship, this study sheds light on the E-HCN frequency of interactions and broadens the scope of research on workplace relationships. ${ }^{4,36,37}$

In the next section, we will explain how the association between personality and performance might be better understood by considering the mediating effect of E-HCN frequency of interactions. Figure 1 summarizes the proposed hypotheses for this study.

\section{Personality and the Frequency of Interactions}

The association between the personality traits of extraversion (ie, being outgoing, energetic, and talkative) and openness (ie, being accepting of change and having a willingness to seek out variety), as well as the impact of these personality traits on career outcomes, have been studied in-depth in domestic settings. ${ }^{38,39}$ It has been suggested that extraversion and openness may also be highly relevant in the study of expatriate assignments and may influence E-HCN relationships. ${ }^{40}$ Furthermore, Osman-Gani and Rockstuhl ${ }^{41}$ stated that differences in personality traits can act as an antecedent that shapes an individual's relationship qualities or how he/she networks with others. In other words, personality differences can influence an individual's choice to accept or reject relationships with their peers, friends, and other people. For instance, Bahatti et $\mathrm{al}^{27}$ demonstrated that in international assignments, circumstances in which expatriates are willing to adapt to the viewpoint of their local peers are assumed to improve the relationship between these two groups of people. This is considered in the openness dimension of personality traits. Extraversion refers to individuals who have an outgoing and energetic personality, which is in contrast with individuals who are solitary and reserved. This trait assists individuals to develop higher levels of interaction with others. ${ }^{42}$ In expatriate studies, people who displayed extraversion were significantly better connected to both other expatriates and to people within the host country. This networking capability lies at the core of extraversion. ${ }^{43}$ Prior

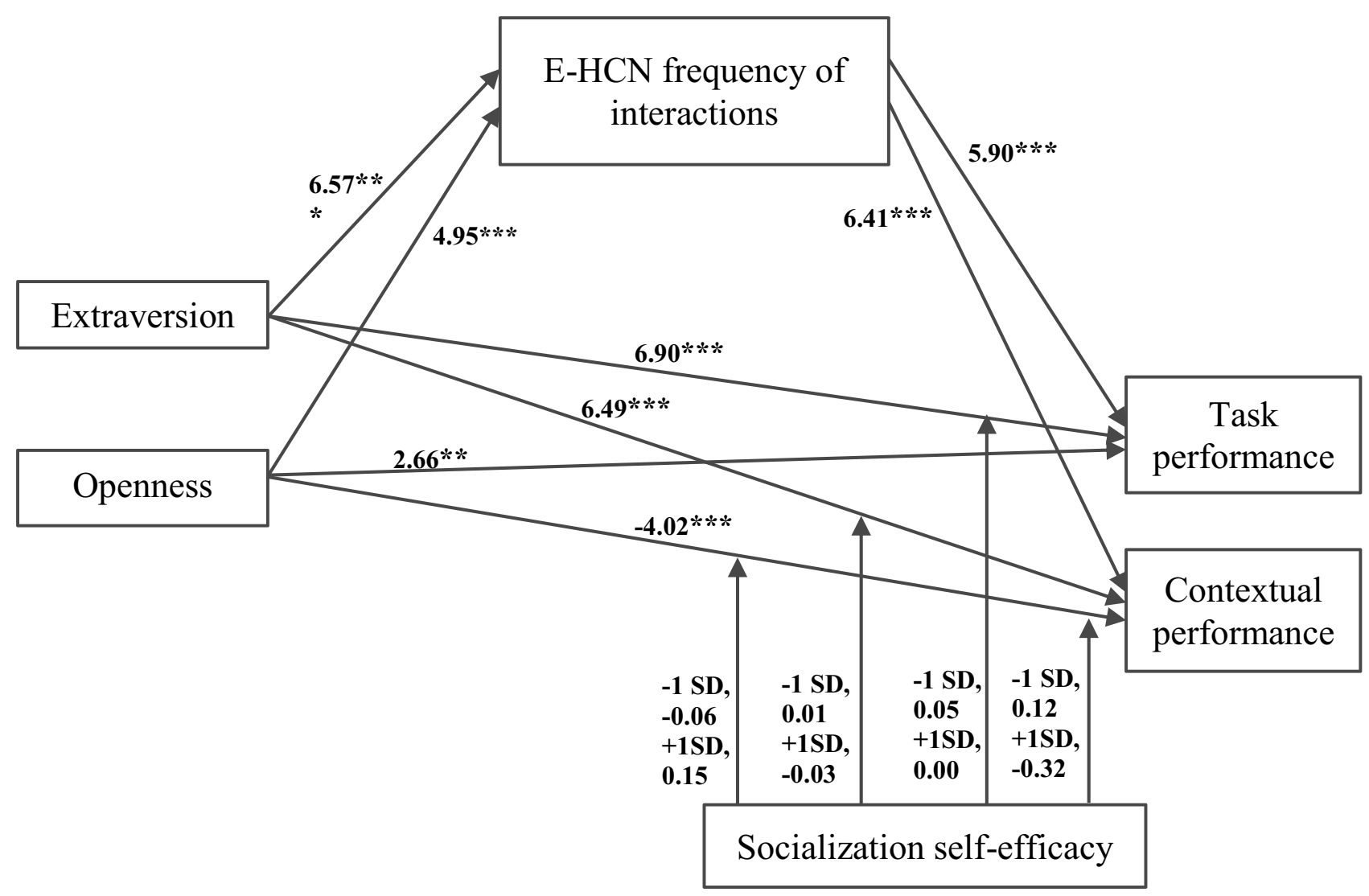

Figure I Proposed theoretical model.

Notes: ${ }^{* *} \mathrm{p}<0.01$; ${ }^{* * *} \mathrm{p}<0.00 \mathrm{I},-\mathrm{I}$ SD as low; + I SD as high values of the moderator. 
research on CEs has found that those high on extraversion are able to better connect with both $\mathrm{HCNs}$ and other expatriates ${ }^{44}$ and those high on openness tend to build better relationships with HCNs. ${ }^{27}$ Previous studies, however, have not examined the association between $\mathrm{HCN}$ personality traits and E-HCN relationship quality.

Cultural differences (ie, language barriers and unfamiliar practices) could mean that HCNs who are engaged in a working relationship with an expatriate may feel vulnerable and experience anxiety. ${ }^{12,45}$ This cultural difference demands the possession of specific cultural competence or cultural intelligence. ${ }^{46,47}$ This study presumed that HCNs' personality trait (extraversion and openness) can act as like a cultural competence that facilitates the adaptation to different cultural environments and assist HCN to have high relationship qualities with their SIE colleagues. Those HCNs who have higher levels of extraversion and openness may be more willing to shift their perspective and view the relationship as a positive means of growth and career development rather than a source of stress. ${ }^{48}$

For instance, Wolff and $\mathrm{Kim}^{43}$ found that expatriates who have high levels of extraversion are more willing to be sociable, more comfortable around local people, less averse to being the center of attention, and therefore adjust more quickly and perform better and faster in the host country than other expatriates. Therefore, those high in extraversion may find people of another culture interesting and could enjoy interacting and learning from them. ${ }^{43}$ Thus, this study presumed that those HCNs who are high in extraversion enjoy interacting with others, which is reflected in their positive behavior and emotions, and may result in a better relationship quality with their SIE colleagues. When SIEs recognize these positive behaviors in their $\mathrm{HCN}$ colleagues, they may feel more comfortable to work with them.

H1a: HCNs with a high level of extraversion will more frequently interact with their expatriate colleagues.

Previous work has also reported that SIEs and HCNs avoid getting close to each other because they are from different cultural backgrounds and consider each other strangers. ${ }^{44}$ However, HCNs who are high in openness are more likely to embrace cultural differences, which helps them to build better relationships more quickly and learn about the culture of SIEs (see Pinto and Araujo, ${ }^{49}$ for review). Therefore, those high on openness may be more likely to embrace cultural differences, thus enabling them to more quickly find or build shared understandings. ${ }^{49}$ Indeed, previous research has found that openness is associated with a lower tendency to avoid those of other races and positive attitudes toward diversity, ${ }^{10}$ which makes it more likely individuals with openness will cooperate with expatriates. By being willing to engage with others and experience new ideas, an $\mathrm{HCN}$ may build stronger relationships by seeking out opportunities to connect with the expatriate he/she works most closely with, behaving in a manner that promotes trusts, and engaging in dialogue that enables a shared vision.

H1b: HCNs with a high level of openness will report a higher frequency of interactions in their E-HCN relationship.

\section{The Mediating Role of the Frequency of Interactions}

Prior research in domestic settings has found that extraversion is a valid predictor of performance for occupations that require social interaction (eg, managers, salespeople), while openness is a valid predictor of performance, regardless of occupation (for a meta-analysis). ${ }^{50}$ Research on the association between CEs' personality and performance has produced similar results. ${ }^{3}$

Personality traits are the distinguishing qualities or characteristics of an individual, including an individual's habitual patterns of behavior, thought, and emotion in various circumstances. ${ }^{35}$ Athota et $\mathrm{al}^{72}$ argued that extraversion and openness play a critical role in increasing organizational performance effectiveness and efficiency. These cross-cultural studies have found that expatriates who have high levels of extraversion and openness should be better able to overcome cultural barriers and more easily adapt to working with those of different cultural backgrounds. ${ }^{27}$ In addition, we expect that HCNs' extraversion and openness to experiences are valid predictors of performance. Through these interactions with expatriates, HCNs may gain knowledge through interactions with expatriates, ${ }^{51}$ and network contacts, which help them to be more productive. ${ }^{34}$

H2a: HCNs with high levels of extraversion and openness will report better task performance.

Likewise, extroverted HCNs are more likely to be comfortable with the amount of social interaction needed to successfully perform the job. ${ }^{76}$ People with this 
characteristic have been described as energetic, active in their participation, confident in communicating their opinions, and avoidant of conflict with the others, which are all qualities that could improve job performance. ${ }^{77}$ Furthermore, HCNs who are high on openness and may be more willing to engage in unfamiliar activities and to consider the values, beliefs, and modes of decision-making that are different from their own. ${ }^{77}$ They may view working with an expatriate as an opportunity to learning and develop their existing knowledge. The greater willingness to learn from expatriates and adopt new ways to approach tasks and problems may mean that HCNs high on openness are, in turn, more productive.

$\mathrm{H} 2 \mathrm{~b}$ : HCNs with high levels of extraversion and openness will report higher levels of contextual performance.

Although past research has examined the positive association between personality traits and performance, ${ }^{50}$ no studies have yet considered how the E-HCN frequency of interactions may influence this association. Given that the frequency of interactions is an important dimension of relationship quality, it could mediate the association between personality traits and HCN performance.

While members of dyadic workplace relationships often experience difficulties, individuals from different cultural backgrounds may encounter even more obstacles in developing high-quality dyadic relationships than those of the similar backgrounds. ${ }^{52}$ Individuals tend to engage in relationships because of perceived similarity in surface characteristics, such as nationality, as described by the similarity-attraction and homophile principles. ${ }^{53}$ Foreign and local employees working together may experience stress because of perceived dissimilarities. For example, HCNs may feel anxious and be uncertain about how to interact with expatriates, especially with expatriates who have social norms and methods of completing tasks that are different to their own. ${ }^{28}$ Furthermore, even if the expatriate and HCN speak the same language, there may be difficulties due to each party's use of slang or rapidness of speaking. The HCN could be nervous that they will not be able to guide the expatriate effectively or that they will be blamed for the expatriate's failures.

Strengthening the E-HCN relationship, however, may help reduce the uncertainty and stress associated with working with someone of a different cultural background. ${ }^{54}$ E-HCN relationships are characterized by a high frequency of interactions that can bolster the bond between the $\mathrm{HCN}$ and expatriate, thus permitting the $\mathrm{HCN}$ to exhibit a higher performance. The frequency of interactions is the number of interactions in personal relationships inside a company, ${ }^{55}$ such as face-to-face communication, video conferencing, phone calls, and email interactions between SIEs and HCNs. Also, practical research has highlighted that a greater number of interactions drives the attachment between two actors. ${ }^{12}$ The parties may share their innermost thoughts and opinions, which permits them to discuss and recognize common core values and beliefs. These interactions may unite the $\mathrm{HCN}$ and expatriate and could provide a crucial bonding mechanism, and, in turn, enhance each party's performance.

To summarize, a high frequency of interactions between HCNs and expatriates may mediate the relationship between personality traits and performance. While the existing literature has placed an emphasis on the role HCNs play in providing informational and emotional support to expatriates, so as to enhance expatriate performance, ${ }^{56}$ interactions between $\mathrm{HCNs}$ and expatriates may also benefit HCNs. Thus, the E-HCN frequency of interactions is likely to be mutually beneficial. Each party will contribute to the other, reinforcing the reciprocal nature of their interactions. ${ }^{33}$ During an international assignment, expatriates may contribute to the global sharing and transferring of knowledge. ${ }^{57}$ Expatriates may also serve as "reserves" of organizational and national culture (ie, embedded and tacit knowledge), but they decide what knowledge to share and with whom. ${ }^{58}$ Overall, when the two parties interact, expatriates may help HCNs gain a different perspective on the multinational company's strategy and objectives, to develop intercultural competences, and connect with a useful network of international contacts.

H3: The association between personality traits and performance will be mediated by the frequency of interactions.

\section{The Moderated Mediation Effect of Socialization Self-Efficacy}

Socialization self-efficacy helps individuals to adapt to new rules, roles, and norms. ${ }^{59,60}$ Prior studies have focused on how HCNs play a critical role in helping expatriates overcome cultural barriers so that they can learn to fit into their work environment. ${ }^{56}$ However, interactions with expatriates may also help HCNs to alter their perspectives and values, such that they can better adjust to changes in their jobs and succeed within their evolving 
work environment. While working with expatriates, HCNs may experience ambiguity and anxiety as they encounter new cultural norms and unfamiliar cultural practices. Expatriates may help to reduce these uncertainties, causing the HCN to change their opinions and behaviors. ${ }^{61}$

In the expatriate literature, two dimensions of socialization self-efficacy, social aspects and social context, are typically used to capture individuals' changes due to their interactions with different cultures. ${ }^{21}$ First, social aspects refer to how HCNs' interactions with foreigners have altered perceptions of their own work roles, as well as the work roles of their subordinates and their expatriate colleagues. For example, through interactions with expatriate colleagues, HCNs may learn new or innovative ways of accomplishing tasks. Second, social context refers to the adjustment made by HCNs in their manner of dress and behaviors due to their relationship with expatriate colleagues. The HCN may view the expatriate as a role model, and so may try to act or dress more like them to fit in better with them. Therefore, we can suggest that the influence of socialization self-efficacy may conditionally influence the strength of the indirect relationship between personality and performance. We propose that socialization self-efficacy influences HCNs' performance by reinforcing the positive relationship between personality (extraversion and openness) and the E-HCN frequency of interactions. Thus, we proposed the following hypotheses:

H4: Socialization self-efficacy will moderate the indirect effect of extraversion on (a) task performance and (b) contextual performance through the frequency of interactions, with a stronger effect seen with a higher (vs lower) level of socialization self-efficacy.

H5: Socialization self-efficacy will moderate the indirect effect of openness on (a) task performance and (b) contextual performance through the frequency of interactions, with a stronger effect seen with a higher (vs lower) level of socialization self-efficacy.

\section{Methods}

\section{Sample and Procedure}

As part of another research project, the first author contacted 1200 SIEs whose email addresses had been obtained from the Chinese Foreign Expert Offices in Hangzhou and Shanghai. Of the 1000 SIEs who participated in that project, 588 provided the email address of an HCN colleague with whom they worked. In this study, we emailed those 588 HCNs, providing them with a link to an online survey and offering 20 Yuan ( $\sim 3.16$ US) for their participation. A total of 373 usable surveys were returned from the $\mathrm{HCNs}$, with a response rate of $63 \%$.

The average age of HCNs was 26 years old $(\mathrm{SD}=$ $3.65)$, and women made up most of the sample (86\%). The majority $(64 \%)$ of $\mathrm{E}-\mathrm{HCN}$ relationships were between peers of equal rank. All the HCNs were Chinese.

\section{Ethics Statement}

Following the 2013 revision of Helsinki Declaration, we designed our research to emulate a medical research study. The study was reviewed and approved by the Zhejiang City College University's ethics committees. The data were volunteered by our study participants and all research participants provided written and informed consent.

\section{Measures}

The following variables were measured using the $\mathrm{HCN}$ survey: personality traits, frequency of interactions, socialization self-efficacy, HCN task and contextual performance, and the control variables (gender, age, and type of E-HCN relationship). Unless otherwise indicated, survey item responses ranged from "strongly disagree" (1) to "strongly agree" (7) and were scored on a seven-point Likert scale.

\section{Personality Traits}

The Big-Five Inventory was used to measure extraversion $(8$ items) and openness (10 items). ${ }^{62}$ The stem, "Do you agree that you are someone who ...", was used with items such as "is talkative" for extraversion and "is original, comes up with new ideas" for openness. The Cronbach's alpha for extraversion was 0.84 , and for openness, it was 0.79 .

The frequency of interactions was measured by McAllister's ${ }^{63} 4$-item scale. Using a 5-point Likert scale ranging from $1=$ never to $5=$ all the time, HCNs rated items, including "How frequently do you interact with your foreigner colleague at work?" and "How frequently do you interact with your foreigner colleague informally or socially at work?". The Cronbach's alpha for frequency of interactions was 0.92 .

\section{Socialization Self-Efficacy}

To measure individual socialization from working with foreign colleagues, we adapted Lee et al's ${ }^{21}$ scale. Six items were used to measure socialization experiences; a sample item is, "I altered my working procedures when 
I began working with foreigner colleagues". The Cronbach's alpha for socialization experiences was 0.86 .

\section{Performance}

The performance was measured using Lee et al's ${ }^{21}$ scale, which examines task (4 items) and contextual (3 items) performance. A sample item for task performance is, "I am performing well and doing my assignment in collaboration with my expatriate colleague/s"'. A sample item for contextual performance is, "I get along well with my expatriate colleagues". The Cronbach's alpha for task performance was 0.85 , and for contextual performance, it was 0.89 . Self-report study provided all the information for both independent and dependent variables from same resource that make the common method bias or validity problem. Therefore, this study to prevent the common method variance ${ }^{64}$ checked the error by conducting "Harman's single factor" techniques in order to claim that there is not a common method variance issue which results displayed $46 \%$ of the variance that is not more than $50 \%$ of the total variance.

\section{Control Variables}

Because the gender and age of SIEs have previously been found to differentiate the level of performance of SIEs, ${ }^{2,8}$ these two variables were controlled. Respondents were asked to indicate their sex, which was coded as $1=$ male and $0=$ female. Age was estimated by direct question to the respondents "How old are you?". Because prior studies suggested that actor similarity increases the quality of E-HCN relationship, ${ }^{11,51}$ relationship type was also documented and was coded as $0=$ not peers (ie, supervisorsubordinate) and $1=$ peers.

\section{Data Analysis Techniques}

The hypotheses were then tested in two interlinked steps. First, a simple mediation model was used to test H1-3 according to the multistep approach proposed by Baron and Kenny. ${ }^{65}$ Second, the PROCESS model and 5000sample bootstrap approach ${ }^{66}$ were used to explore the possible mediation. The effects of independent variable $\mathrm{X}$ (personalities) and mediator $\mathrm{M}$ (frequency of interaction) on outcome Y (performance) were examined (H3). Finally, the proposed moderated mediation (H4 and 5) was examined using the approach designed by Preacher et al ${ }^{67}$ to operationalized the conditional indirect effect of personalities on performance at high and low levels of socialization self-efficacy. The PROCESS model and 5000-sample bootstrap approach were used.

\section{Common Method Variance}

A confirmatory factor analysis was performed to test whether the hypothesized model captured distinct constructs $^{64}$ using AMOS 22.0. The hypothesized sixfactor model fit the data acceptably and captured distinct constructs, with $\chi^{2}(169 d f)=369.91, \mathrm{CFI}=0.97$, TLI $=$ 0.95, RMSEA $=0.05$, and $\mathrm{SRMR}=0.04$. All of the observed items loaded on their respective latent factors, and the factor loadings were all significant, indicating that the latent variables had acceptable convergent validity. In addition, we compared the hypothesized model to three alternative models. The first alternative five-factor model specified loading of extraversion and openness on one latent factor, with the other variables loading on their respective factors. This alternative model fits worse than the hypothesized model $\left(\chi^{2}(113 d f)=1044.951\right.$, CFI $=0.90, \mathrm{TLI}=0.89, \quad R M S E A=0.06$, and $\mathrm{SRMR}=0.09$ ). The second alternative five-factor model specified loading of task and contextual performance on one latent factor, with the other variables loading on their respective factors. The second alternative model fit worse than the hypothesized model $\left(\chi^{2}(111 d f)=1221.251, \mathrm{CFI}=0.88, \mathrm{TLI}=0.87\right.$, $R M S E A=0.07$, and SRMR $=0.08$ ). The third alternative four-factor model specified loading of extraversion, openness, and E-HCN frequency of interaction on one latent factor, with the other variables loading on their respective factors. The third alternative model fits worse than the hypothesized model $\left(\chi^{2}(108 d f)=1573.389\right.$, CFI $=0.82$, $\mathrm{TLI}=0.81, R M S E A=0.09$, and SRMR $=0.08$ ). Overall, the analyses indicated that the five constructs captured distinctiveness and exhibited a theoretically meaningful structure. These findings suggest that the covariance structure was probably not dominated by CMV.

\section{Results}

\section{Test of Mediation Effects}

Hypothesis 1 was that $\mathrm{HCNs}$ with high levels of (a) extraversion and (b) openness will report a greater of frequency of interactions in their E-HCN relationship. As can be seen in Table 2, Table 1 extraversion $(\beta=0.28, t=$ $0.05, p<0.001)$ and openness $(\beta=0.36, t=0.09, p<$ 0.001 ) were positively associated with the frequency of interactions, thus supporting $\mathrm{H} 1 \mathrm{a}$ and $\mathrm{H} 1 \mathrm{~b}$. 
Table I Descriptive Statistics, Reliabilities, and Intercorrelations

\begin{tabular}{|c|c|c|c|c|c|c|c|c|c|c|}
\hline Variables & $\mathbf{M}$ & SD & $\mathbf{I}$ & 2 & 3 & 4 & 5 & 6 & 7 & 8 \\
\hline I. Extraversion & 4.95 & 0.91 & $(0.84)$ & & & & & & & \\
\hline 2. Openness & 5.33 & 0.75 & $0.10^{*}$ & $(0.79)$ & & & & & & \\
\hline 3. Frequency of interactions & 4.06 & 1.19 & $0.55 * *$ & $0.21 * *$ & $(0.92)$ & & & & & \\
\hline 4. Socialization self-efficacy & 5.22 & 1.12 & $0.49 * *$ & $0.23 * *$ & $0.33^{* *}$ & $(0.86)$ & & & & \\
\hline 5. Task performance & 3.58 & 1.36 & $0.33 * *$ & $0.17 * *$ & $0.21^{* *}$ & $0.16 * *$ & $(0.85)$ & & & \\
\hline 6. Contextual performance & 3.36 & 1.64 & $0.32 * *$ & -.04 & $0.42 * *$ & $0.21 * *$ & $0.45^{* *}$ & $(0.89)$ & & \\
\hline 7. Gender & 0.69 & 0.46 & -.07 & $0.14 * *$ & $-.25 * *$ & $-.20 * *$ & 0.09 & -.04 & - & \\
\hline 8. Age & 30.0 & 8.82 & -.03 & 0.04 & $-.28 * *$ & -.03 & $-.19 * *$ & $-.26 * *$ & $0.34 * *$ & - \\
\hline 9. Relationship type & 1.65 & 0.66 & $0.11 *$ & -.07 & 0.00 & $0.12^{*}$ & -.01 & -.09 & -.06 & -.04 \\
\hline
\end{tabular}

Notes: HCNs: $n=(373)$; Alpha reliabilities are shown in parentheses on the diagonal line. For the sex variable, men were coded as I and women were coded as 0 . For relationship type, non-peer relationships were coded as 0 and peer relationships were coded as $1 .{ }^{*} p<0.05 ; * * p<0.0$ I.

Table 2 Regression Results for Simple Mediation $(n=249)$

\begin{tabular}{|l|c|c|c|c|c|c|c|c|c|}
\hline & \multicolumn{3}{|c|}{ Frequency of Interactions } & \multicolumn{3}{c|}{ Task Performance } & \multicolumn{3}{c|}{ Contextual Performance } \\
\hline Variables & $\boldsymbol{\beta}$ & $\mathbf{S E}$ & $\mathbf{t}$ & $\boldsymbol{\beta}$ & $\mathbf{S E}$ & $\mathbf{t}$ & $\boldsymbol{\beta}$ & $\mathbf{S E}$ & $\mathbf{t}$ \\
\hline Extraversion & 0.28 & 0.05 & $6.57^{* * *}$ & 0.43 & 0.08 & $6.90^{* * *}$ & 0.50 & 0.09 & $6.49 * * *$ \\
Openness & 0.36 & 0.09 & $4.95^{* * *}$ & 0.24 & 0.09 & $2.66^{* *}$ & -0.39 & 0.09 & $-4.02^{* * *}$ \\
Frequency of interaction & & & & 0.30 & 0.05 & $5.90^{* * *}$ & 0.43 & 0.06 & $6.4 I^{* * *}$ \\
Sex (Male) & -0.36 & 0.12 & $-2.85^{* *}$ & 0.39 & 0.15 & $3.93^{* * *}$ & 0.30 & 0.17 & 1.73 \\
Age & -0.01 & 0.06 & $-2.64 * *$ & -0.03 & 0.07 & $-4.79 * * *$ & -0.05 & 0.09 & $-5.73^{* * *}$ \\
Relationship type & -0.06 & 0.12 & -0.49 & 0.11 & 0.14 & 0.48 & 0.01 & 0.16 & 0.11 \\
\hline
\end{tabular}

Notes: **p $<0.01$; ***p $<0.001$.

Hypothesis 2 was that HCNs with high levels of extraversion and openness will report higher levels of (a) task and (b) contextual performance. As shown in Table 2, extraversion $(\beta=0.43, t=0.08, p<0.001)$ and openness $(\beta=0.24, t=0.09, p<0.001)$ were positively related to HCN task performance, thus supporting H2a. Similarly, extraversion $(\beta=0.50, t=0.09, p<0.001)$ was positively associated with contextual performance; however, openness was negatively associated with contextual performance $(\beta=-0.39, t=0.09, p<0.001)$. Therefore, $\mathrm{H} 2 \mathrm{~b}$ was partially supported.

Hypothesis 3 was that the relationship between personality traits and performance would be mediated by frequency of interaction. As shown in Table 3, the frequency of interactions fully mediated the relationship between extraversion and task performance (Effect size $=0.39$, Boot $\mathrm{SE}=0.05 ; 95 \% \mathrm{CI}[0.2964$, 0.5002]) and between openness and task performance (Effect size $=0.49$, Boot $\mathrm{SE}=0.06$; 95\% CI $[0.3028$, $0.5553])$. The frequency of interactions fully mediated the relationship between openness and contextual performance (Effect size $=0.20$, Boot $\mathrm{SE}=0.04 ; 95 \% \mathrm{CI}$ $[0.1147,0.3013])$ and between openness and contextual performance (Effect size $=0.29$, Boot $\mathrm{SE}=0.05$; $95 \%$ CI $[0.1750,0.4082])$. Therefore, H3 was supported.

Table 3 The Indirect Effects of the Independent Variables on Outcomes

\begin{tabular}{|c|c|c|c|c|}
\hline Independent Variables & Outcomes & Effect & Boot SE & $95 \% \mathrm{Cl}$ \\
\hline \multirow[t]{2}{*}{ Extraversion } & Task performance & 0.39 & 0.05 & {$[0.2964,0.5002]$} \\
\hline & Contextual performance & 0.49 & 0.06 & {$[0.3028,0.5553]$} \\
\hline \multirow[t]{2}{*}{ Openness } & Task performance & 0.20 & 0.04 & {$[0.1|47,0.30| 3]$} \\
\hline & Contextual performance & 0.29 & 0.05 & {$[0.1750,0.4082]$} \\
\hline
\end{tabular}

Note: Bootstrap sample size: 5000 .

Abbreviation: $\mathrm{Cl}$, confidence interval. 


\section{Test of Moderated Mediation Effects}

Hypothesis 4 was that socialization self-efficacy would moderate the mediated effects of openness on (a) task and (b) contextual performance via the frequency of interactions. As shown in Table 4, at lower levels of socialization self-efficacy, extraversion did not have an indirect effect on task performance via the frequency of interactions $(b=-0.06,95 \%$ CI $[-0.2360,0.1109])$. At higher levels of socialization self-efficacy, extraversion had an indirect effect on task performance via the frequency of interactions $(b=-0.03,95 \% \mathrm{CI}[0.0205,0.2923])$. At lower levels of socialization self-efficacy, extraversion did not have an indirect effect on contextual performance via the frequency of interactions $(b=0.01,95 \%$ CI $[-0.0717$, $0.2287]$ ); at higher levels of socialization self-efficacy, extraversion did not have an indirect effect on contextual performance via the frequency of interactions $(b=-0.03$, $95 \%$ CI $[-0.1668,0.0460])$. Therefore, H4a was supported and $\mathrm{H} 4 \mathrm{~b}$ was not supported.

Likewise, at lower levels of socialization self-efficacy, openness did have not an indirect effect on task performance via the frequency of interactions $(b=0.05,95 \% \mathrm{CI}$ $[-0.0105,0.1340])$; at higher levels of socialization selfefficacy, openness did not have an indirect effect on task

Table 4 The Conditional Indirect Effect of Personality on Performance at High and Low Levels of Socialization Self-Efficacy

\begin{tabular}{|c|c|c|c|}
\hline Moderator & Effect & Boot SE & $95 \% \mathrm{Cl}$ \\
\hline \multicolumn{4}{|c|}{$\begin{array}{l}\text { The conditional indirect effect of extraversion on task performance at } \\
\text { high and low levels of socialization self-efficacy }\end{array}$} \\
\hline Low (-I SD) & -0.06 & 0.08 & {$[-0.2360,0.1109]$} \\
\hline High (+I SD) & 0.15 & 0.06 & {$[0.0205,0.2923]$} \\
\hline \multicolumn{4}{|c|}{$\begin{array}{l}\text { The conditional indirect effect of extraversion on contextual } \\
\text { performance at high and low levels of socialization self-efficacy }\end{array}$} \\
\hline Low (-I SD) & 0.01 & 0.08 & {$[-0.0717,0.2287]$} \\
\hline High (+I SD) & -0.03 & 0.11 & {$[-0.1668,0.0460]$} \\
\hline \multicolumn{4}{|c|}{$\begin{array}{l}\text { The conditional indirect effect of openness on task performance at } \\
\text { high and low levels of socialization self-efficacy }\end{array}$} \\
\hline Low (-I SD) & 0.05 & 0.03 & {$[-0.0105,0.1340]$} \\
\hline High (+I SD) & 0.00 & 0.02 & {$[-0.0541,0.0586]$} \\
\hline \multicolumn{4}{|c|}{$\begin{array}{l}\text { The conditional indirect effect of openness on contextual } \\
\text { performance at high and low levels of socialization self-efficacy }\end{array}$} \\
\hline Low (-I SD) & 0.12 & 0.13 & {$[-0.1416,0.3883]$} \\
\hline High (+I SD) & -0.32 & 0.14 & {$[-0.6159,-0.0396]$} \\
\hline
\end{tabular}

Note: Bootstrap sample size: 5000

Abbreviation: $\mathrm{Cl}$, confidence interval. performance via the frequency of interactions $(b=0.00$, $95 \%$ CI [-0.0541, -0.0586]). However, at lower levels of socialization self-efficacy, openness had not an indirect effect on contextual performance via the frequency of interactions $(b=0.12,95 \% \mathrm{CI}[-0.1416,0.3883])$; at higher levels of socialization self-efficacy, openness had an indirect effect on contextual performance via the frequency of interactions $(b=-0.32,95 \%$ CI $[-0.6159,-0.0396])$. Thus, $\mathrm{H} 5 \mathrm{a}$ was not supported and H5b was supported.

To further examine the moderating effect of socialization experiences, we used the Johnson-Neyman technique. ${ }^{66,67}$ Figure $2 \mathrm{~A}$ depicts the plot of the conditional indirect effect of extraversion on task performance via socialization self-efficacy. The indirect effect of extraversion on task performance via the frequency of interactions was significantly far from zero when the value of socialization self-efficacy was greater than 5.8. The indirect effect gradually decreased as the moderator increased. Thus, while socialization efficacy did moderate the mediated effects of extraversion on task performance via the frequency of interactions, the effect of extraversion on task performance through the frequency of interactions was stronger when socialization self-efficacy was high. Therefore, H4a was supported.

Figure 2B depicts the plot of the conditional indirect effect of openness on contextual performance via socialization self-efficacy. The indirect effect of openness on contextual performance via frequency of interaction was significantly far from zero when the value of socialization self-efficacy was greater than 5.9. The indirect effect gradually decreased as the moderator increased. Thus, while socialization self-efficacy did indeed moderate the mediated effects of openness on contextual performance via the frequency of interactions, this was not in the hypothesized direction. Instead, the effect of openness on contextual performance through frequency of interaction was weaker when socialization selfefficacy was high. Therefore, H5b was only partially supported.

\section{Discussion}

This study focused on the neglected actor in the E-HCN frequency of interactions, namely HCNs. We examined how personality traits (extraversion and openness) and the E-HCN frequency of interactions influence HCNs' performance. Besides this, this paper also highlights the role of the moderated mediation of frequency of interactions and socialization self-efficacy. 


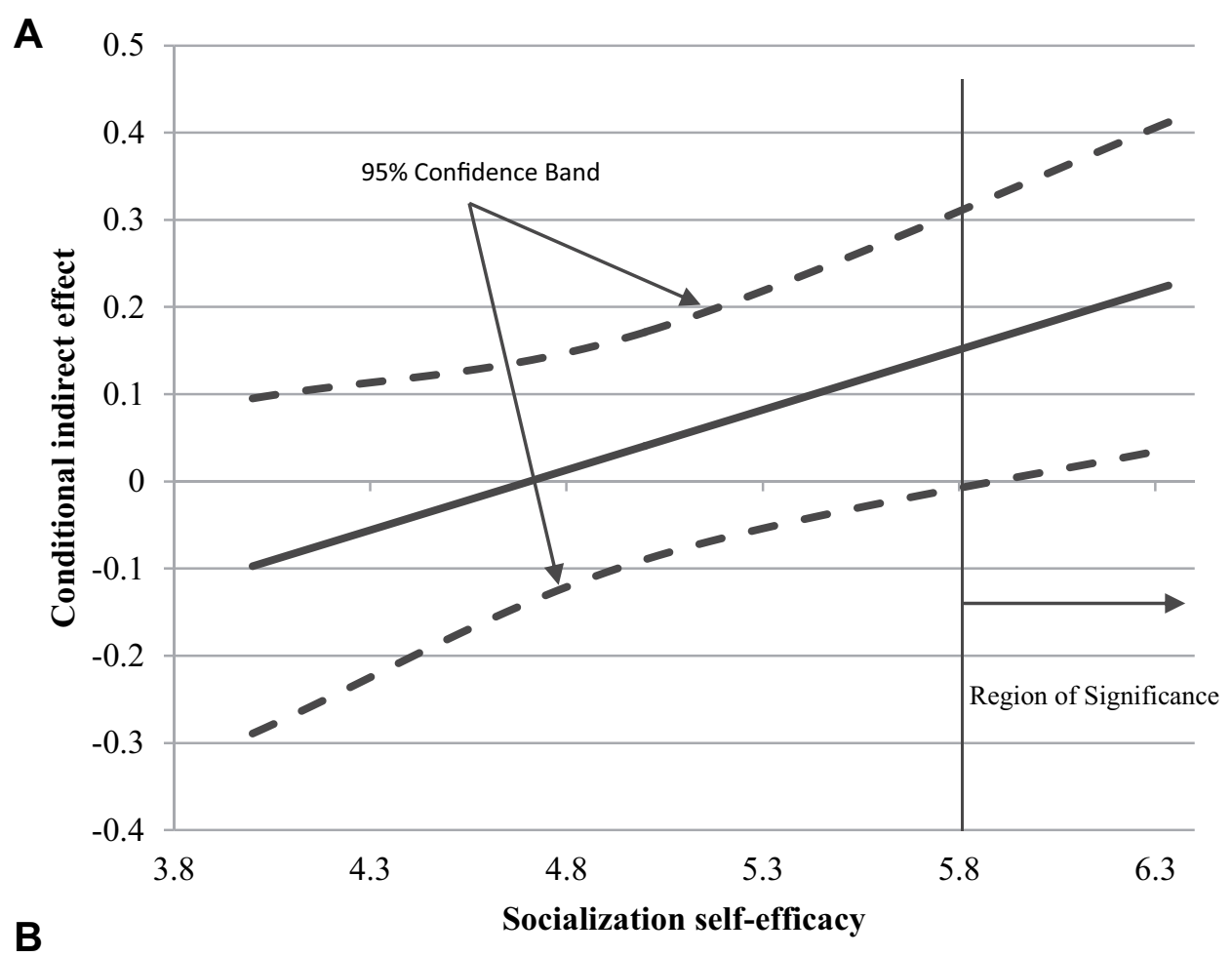

B

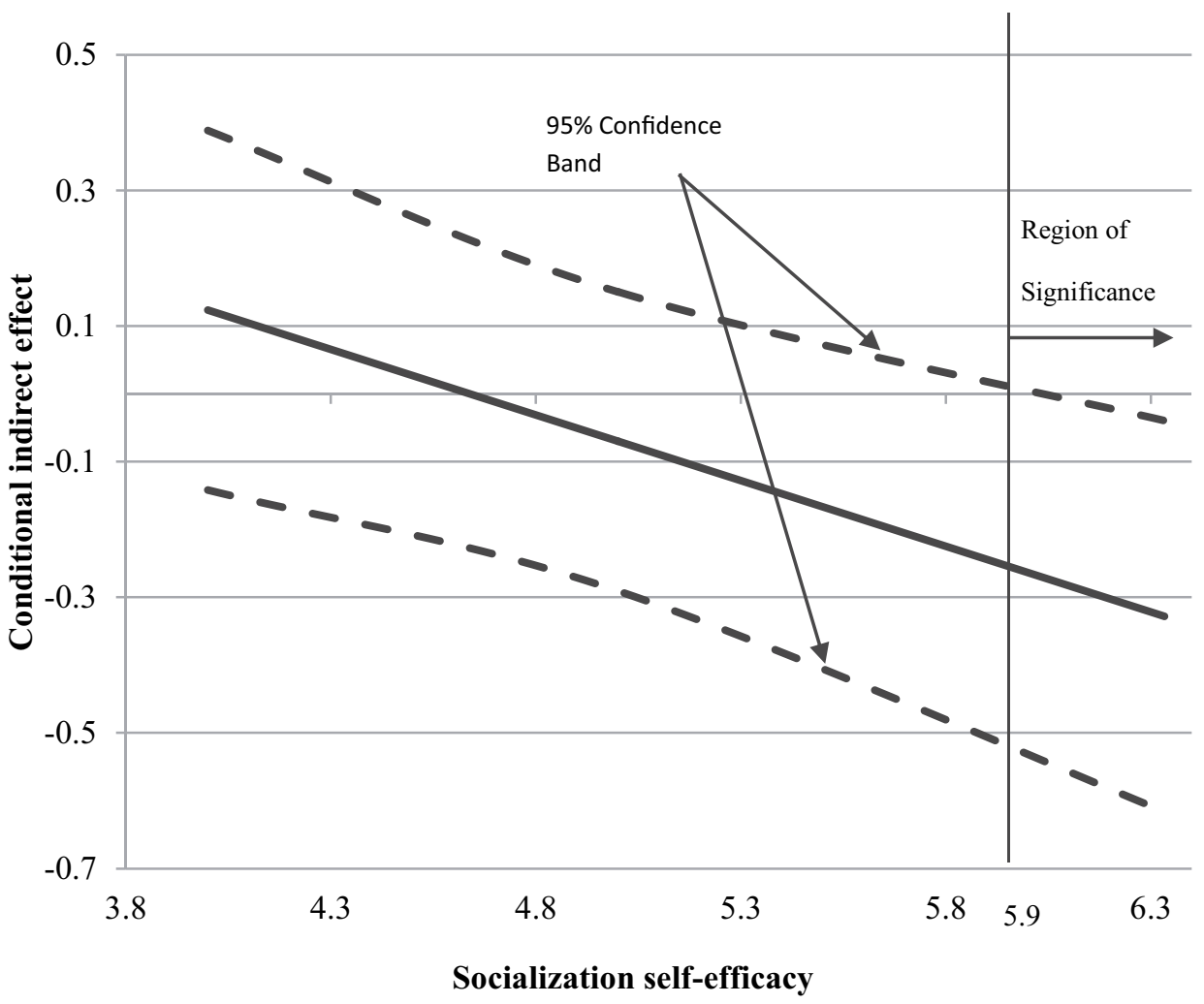

Figure 2 (A) Interaction between the indirect effect of extraversion and socialization self-efficacy on task performance; (B) interaction between the indirect effect of openness and socialization self-efficacy on contextual performance.

\section{Theoretical Implications}

As predicted by the extraversion-openness model, ${ }^{43}$ we found that extraversion and openness in $\mathrm{HCNs}$ were positively associated with the E-HCN frequency of interactions (H1a, H1b). One theoretical contribution of this study is how personality traits $^{68}$ can work as 
a combination of competencies to help HCNs to increase the frequency of interactions with their SIE colleagues. Furthermore, our findings suggest that extroverted HCNs are assertive and talkative, which could help them to positively interact with expatriates and develop better relationships with them. $\mathrm{HCNs}$ who are more willing to experience new things, including foreign cultures, might interact with others more positively.

Likewise, HCNs with higher levels of extraversion also had a better task and contextual performance; openness was also positively associated with task performance. The findings of this study suggested that HCNs who are high in extraversion enjoy interacting with others and that this is reflected by their positive behavior and emotions and may result in better relationships between HCNs and their SIE colleagues. Also, the present findings found that openness is associated with HCNs' networking ability and tendency to embrace new experiences, such as new cultures, values, and beliefs. This could help them to react positively to SIEs' cultural differences, thus improving HCNs' job performance and productivity. Therefore, our empirical findings support the theoretical viewpoint of Black and Gregersen. $^{24}$ However, openness was negatively associated with contextual performance $(\mathrm{H} 2)$. One possible explanation for this finding is that HCNs are likely to classify SIEs as outgroup members and treat them accordingly. ${ }^{74}$ This is especially so in China due to its collectivist culture. ${ }^{75}$ Therefore, it may be the case that HCNs are more open to new experiences when these are relevant to their task accomplishment rather than to interpersonal relationships with their SIE colleagues.

Furthermore, the present findings contribute to the concept of relationship quality. ${ }^{4}$ We also found a significant mediation effect of the E-HCN frequency of interactions on the relationship between personality traits and performance. Drawing from social capital theory, ${ }^{31}$ we hypothesized that E-HCN frequency of interactions helped the expatriate and the $\mathrm{HCN}$ to form a bond. Thus, it appears that E-HCN frequency of interactions, as a possible way to increase relationship quality, has a high explanatory value for explaining the association between personality and performance. Other factors, such as the level of organizational support to HCNs engaged in working relationships with expatriate colleagues, may also help explain this association. Our study is the first to report that the frequency of interactions mediates this relationship, and identified which personality traits (extraversion and openness) can enhance the frequency of interactions between SIEs and HCNs, and in turn lead to a better performance. In addition, Shaffer et $\mathrm{al}^{69}$ highlighted that no previous studies have clearly examined the influence of personality traits on job performance in cross-cultural contexts, especially among E-HCN colleagues. Therefore, this study additionally supports cross-cultural studies of HCNs and how personality traits can impact performance via the E-HCN frequency of interactions. ${ }^{70}$

This study also built upon past research that has examined the effect of socialization self-efficacy on expatriate outcomes. $^{21}$ Specifically, we examined how socialization self-efficacy could help HCNs more readily interact frequently with their expatriate colleagues, who are likely to have different cultural backgrounds and beliefs. ${ }^{13} \mathrm{We}$ found that socialization self-efficacy moderated the mediated effect of extraversion on the task performance through the frequency of interactions. The effect of socialization self-efficacy on the relationship between extraversion and task performance was strengthened when socialization self-efficacy was high vs when it was low. As predicted by hypothesis $5 \mathrm{~b}$, socialization self-efficacy moderated the mediated effect of openness on the contextual performance through the frequency of interactions. However, the moderated mediation effect of socialization self-efficacy was not in the expected direction. The effect of socialization self-efficacy on the relationship between openness and contextual performance was weaker when socialization self-efficacy was high versus when it was low. One possible explanation for this finding is that an increased frequency of interactions and more socializing could help HCNs to change their perspective and thus to learn about SIEs' cultural norms and values, which in turn improves the HCN-SIE relationship quality. This interpretation could explain the negative relationship found between openness and contextual performance with fewer interactions when socialization self-efficacy was high vs when it was low. Another theoretical contribution of this study is that it adds weight to the role of socialization self-efficacy, as reported in the $\mathrm{HCN}$ literature, which has focused on how E-HCNs learn about each other's culture and behavior. ${ }^{71}$

Although SIE studies ${ }^{71}$ emphasized the role of the attitudes and behaviors among $\mathrm{HCNs}$ and how they have a positive effect on the SIEs' work success and boost to learn about local cultural norms, just a few studies have observed the role of HCNs on SIEs. ${ }^{12}$ Traditional SIEs research is SIEs-centric in that it neglects the roles of HCNs. ${ }^{6}$ This study fills this research gap by incorporating 
HCNs' perspectives in the process of performance. Thus, the implication of this study, to help SIEs and HCNs in terms of perceiving different situations/environments and provides guidance on how to cope and cooperate with each other.

\section{Practical Implications}

The present findings have two major implications for the management of E-HCN relationships and HCNs' performance. First, this study underscores the importance of the influence of E-HCN frequency of interactions on HCNs' performance. Organizations tend to focus on preparing and training expatriate managers for an international assignment, without considering how to best train $\mathrm{HCNs}$ to interact effectively with expatriates. Organizations should help HCNs recognize the benefits of working with expatriates, such as gaining new knowledge, making network contacts, and career growth. Organizations should provide training to HCNs to help them understand cultural differences and how to overcome obstacles that might impede the development of high-quality E-HCN relationships. Such training may also help HCNs learn to manage the stress that is often associated with working closely with those of different cultural backgrounds. Additionally, managers should create a supportive organizational climate that encourages the development of trust and shared visions between HCNs and expatriates. For example, as HCNs begin to adapt to new norms and learn new ways to perform tasks through their interactions with expatriates, managers and fellow employees should support such changes. Training, coupled with supportive human resource practices, may enhance the frequency of interactions in E-HCN relationships.

Second, this study found that both extraversion and openness were significantly and positively related to the frequency of interactions. These findings suggest that organizations should select HCNs with high extroversion and openness to work closely with expatriates. HCNs with high extraversion and openness are more likely to effectively develop high-quality interactions with expatriates. Also, we found sex differences in the frequency of interactions, whereby female HCNs had more interactions than did male HCNs. While additional research is needed, female HCNs in China may be better able to create effective working relationships with expatriates, which suggests that male HCNs in China may require additional coaching on how to build effective E-HCN relationships.

\section{Limitations and Implications for Future Research}

This study has some limitations that should be noted. First, this study used a cross-sectional design, which did not allow us to observe changes in the frequency of interactions and performance over time. Moreover, we captured the experiences of only one member of the E-HCN relationship. Future studies should use a longitudinal approach and should collect data from both HCNs and expatriates. Collecting data from matched samples would permit, for example, the examination of the effect of similarity in surface characteristics, such as sex and age, upon relationship quality, and whether the influence of surface characteristics may diminish over time. Second, this study examined task and contextual performance, but failed to consider other important work outcomes. Future studies should consider how the frequency of interactions might mediate the association between personality traits and outcomes such as job satisfaction, organizational commitment, and knowledge sharing. Third, this study was conducted in China, and all HCNs surveyed were from China. Future research should therefore test this study's hypotheses in different cultural contexts. The potential influence of contextual factors, including organizational factors and the cultural distance between the HCNs and expatriates, should also be examined.

In sum, this $\mathrm{HCN}$-centralized study examined E-HCN relationships. As the boundaries between countries become more easily crossed, and as an increasing number of individuals become CEs or SIEs, a better understanding of how $\mathrm{HCNs}$ are affected by their interactions with expatriates and how these interactions may influence their performance and other work outcomes is an area worthy of future research. We hope that this study encourages more research on HCNs, who continue to be a neglected stakeholder in the expatriation process.

\section{Funding}

This research was supported by Zhejiang Provincial Natural Science Foundation of China under Grant No. LQ20G020009.

\section{Disclosure}

The authors report no conflicts of interest in this work. 


\section{References}

1. ManpowerGroup. Solving the Talent Shortage: Build, Buy, Borrow and Bridge. 2018.

2. Doherty N. Understanding the self-initiated expatriate: a review and directions for future research. Int J Manag Rev. 2013;15(4):447-469. doi:10.1111/ijmr.12005

3. Kraimer M, Bolino M, Mead B. Themes in expatriate and repatriate research over four decades: what do we know and what do we still need to learn? Annu Rev Organ Psychol Organ Behav. 2016;3 (1):83-109. doi:10.1146/annurev-orgpsych-041015-062437

4. Sharma RR. Cultural intelligence and institutional success: the mediating role of relationship quality. J Int Manag. 2019;25(3):100665. doi:10.1016/j.intman.2019.01.002

5. Biemann T, Andresen M. Self-initiated foreign expatriates versus assigned expatriates. $J$ Manag Psychol 2010;25(4):430-448. doi:10.1108/02683941011035313

6. Baruch Y, Forstenlechner I. Global careers in the Arabian Gulf. Career Dev Int. 2017;22(1):3-22. doi:10.1108/CDI-12-2015-0164

7. Dabic M, González-Loureiro M, Harvey M. Evolving research on expatriates: what is 'known' after four decades (1970-2012). Int $J$ Human Res Manag. 2015;26(3):316-337. doi:10.1080/ 09585192.2013.845238

8. Jannesari M, Sullivan SE. Career adaptability and the success of self-initiated expatriates in China. Career Dev Int. 2019;24 (4):331-349. doi:10.1108/CDI-02-2019-0038

9. Takeuchi R. A critical review of expatriate adjustment research through a multiple stakeholder view: progress, emerging trends, and prospects. J Manag. 2010;36(4):1040-1064. doi:10.1177/0149206 309349308

10. Arman G, Aycan Z. Host country nationals' attitudes toward expatriates: development of a measure. Int $J$ Human Resour Manag. 2013;24(15):2927-2947. doi:10.1080/09585192.2013.763839

11. Varma A, Pichler S, Budhwar P, Kupferer S. Expatriate-local interactions: an investigation in China. J Manag Psychol. 2012;27 (7):753-768. doi:10.1108/02683941211259557

12. Jannesari M, Wang Z, McCall J, Zheng B. Psychological availability between self-initiated expatriates and host country nationals during their adjustment: the moderating role of supportive supervisor relations. Front Psychol. 2017;8:2049. doi:10.3389/fpsyg.2017.02049

13. Fee A, Gray SJ. Expatriates as catalysts: what and how Vietnamese locals learn from self-initiated expatriates. Cross Cult Strateg Manag. 2020;27(3):389-416. doi:10.1108/CCSM-08-2019-0145

14. Rafiq A, Saleem S, Bashir M, Ali A. The paradox role of extraversion in the cross-cultural adjustment process of Asian expatriates. Psychol Res Behav Manag. 2019;12:179. doi:10.2147/PRBM.S191805

15. Mahajan A. Host country national's reactions to expatriate pay policies: making a case for a cultural alignment pay model. Int J Human Resour Manag. 2011;22(01):121-137. doi:10.1080/09585192.20 11.538973

16. Toh SM, Denisi AS. Host country national reactions to expatriate pay policies: a model and implications. Acad Manag Rev. 2003;28 (4):606-621. doi:10.5465/amr.2003.10899387

17. van Bakel M. It takes two to tango: a review of the empirical research on expatriate-local interactions. Int J Human Resour Manag. 2019;30 (21):2993-3025. doi:10.1080/09585192.2018.1449763

18. Al Ariss A, Syed J. Capital mobilization of skilled migrants: a relational perspective. Bus J Manag. 2011;22(2):286-304. doi:10.1111/j.1467-8551.2010.00734.x

19. Kraimer ML, Wayne SJ, Jaworski RAA. Sources of support and expatriate performance: the mediating role of expatriate adjustment Pers Psychol. 2001;54(1):71-99. doi:10.1111/j.1744-6570.2001. tb00086.x

20. Caligiuri P, Baytalskaya N, Lazarova MB. Cultural humility and low ethnocentrism as facilitators of expatriate performance. $J$ Glob Mobility. 2016;4(1):4-17. doi:10.1108/JGM-03-2015-0007
21. Lee LY, Veasna S, Wu WY. The effects of social support and transformational leadership on expatriate adjustment and performance. Career Dev Int. 2013;18(4):377-415. doi:10.1108/CDI-06-2012-0062

22. Mol ST, Born MP, Willemsen ME, Van Der Molen HT. Predicting expatriate job performance for selection purposes: a quantitative review. J Cross Cult Psychol. 2005;36(5):590-620. doi:10.1177/ 0022022105278544

23. Guang X, Charoensukmongkol P. The effects of cultural intelligence on leadership performance among Chinese expatriates working in Thailand. Asian Bus Manag. 2020;1-23. doi:10.1057/s41291-020-00112-4

24. Black JS, Gregersen HB. Antecedents to cross-cultural adjustment for expatriates in Pacific Rim assignments. Hum Relat. 1991;44 (5):497-515. doi:10.1177/001872679104400505

25. Wang D, Freeman S, Zhu CJ. Personality traits and cross-cultural competence of Chinese expatriate managers: a socio-analytic and institutional perspective. Int J Human Resour Manag. 2013;24 (20):3812-3830. doi:10.1080/09585192.2013.778314

26. Selmer J, Lauring J, Zhang LE, Jonasson C. How do assigned and selfinitiated expatriate CEOs differ? An empirical investigation on CEO demography, personality, and performance in China. In: Global Talent Management and Staffing in MNEs. London: Emerald Group Publishing Limited; 2016:49-79. doi10.1108/S1876-066X20160000032002

27. Bhatti MA, Battour MM, Ismail AR, Sundram VP. Effects of personality traits (big five) on expatriates adjustment and job performance. Equal Divers Incl. 2014. doi:10.1108/EDI-01-2013-0001

28. Selmer J, Lauring J, Normann J, Kubovcikova A. Context matters: acculturation and work-related outcomes of self-initiated expatriates employed by foreign vs. local organizations. Int J Intercult Relat. 2015;49:251-264. doi:10.1016/j.ijintrel.2015.05.004

29. Burt RS. Structural Holes: The Social Structure of Competition. Harvard university press; 2009.

30. Granovetter MS. Getting a job. Cambridge, MA: Harvard University Press; 1974.

31. Nahapiet J, Ghoshal S. Social capital, intellectual capital, and the organizational advantage. Acad Manag Rev. 1998;23(2):242-266. doi:10.5465/amr.1998.533225

32. Kogut B, Zander U. Knowledge of the firm, combinative capabilities, and the replication of technology. Org Sci. 1992;3(3):383-397. doi:10.1287/orsc.3.3.383

33. Forret ML, Dougherty TW. Correlates of networking behavior for managerial and professional employees. Group Organ Manag. 2001;26(3):283-311. doi:10.1177/1059601101263004

34. Forret ML. Networking as a job search and career management behavior. In: Klehe UC \& van Hooft EWJ, editors. The Oxford handbook of job loss and job search. New York: Oxford University Press; 2018:275.

35. McCrae RR, Costa JPT. Personality trait structure as a human universal. Am Psychol. 1997;52(5):509. doi:10.1037/0003-066X.52.5.509

36. Methot JR, Melwani S, Rothman NB. The space between us: a social-functional emotions view of ambivalent and indifferent workplace relationships. J Manag. 2017;43(6):1789-1819. doi:10.1177/ 0149206316685853

37. Yao C, Duan Z, Baruch Y. Time, space, confucianism and careers: a contextualized review of careers research in China-Current knowledge and future research agenda. Int J Manag Rev. 2020;22 (3):222-248. doi:10.1111/ijmr.12223

38. Huang JL, Ryan AM, Zabel KL, Palmer A. Personality and adaptive performance at work: a meta-analytic investigation. J Appl Psychol. 2014;99(1):162. doi:10.1037/a0034285

39. Yao H, Jannesari MT, Sun J, Lai Q, Ji J. Impact of sense of status on the international entrepreneurial intention of undergraduates in China. Soc Behav. 2020;48(10):1-12. doi:10.2224/sbp.9408

40. Lauring J, Selmer J, Kubovcikova A. Personality in context: effective traits for expatriate managers at different levels. Int J Human Resour Manag. 2019;30(6):1010-1035. doi:10.1080/09585192.2017.13 81137 
41. Osman-Gani AM, Rockstuhl T. Antecedents and consequences of social network characteristics for expatriate adjustment and performance in overseas assignments: implications for HRD. Hum Resour Dev Rev. 2008;7(1):32-57. doi:10.1177/1534484307312182

42. Taggar S, Neubert M. The impact of poor performers on team outcomes: an empirical examination of attribution theory. Pers Psychol. 2004;57(4):935-968. doi:10.1111/j.1744-6570.2004.00011.x

43. Wolff HG, Kim S. The relationship between networking behaviors and the big five personality dimensions. Career Dev Int. 2012;17 (1):43-66. doi:10.1108/13620431211201328

44. Fee A, McGrath-Champ S. The role of human resources in protecting expatriates: insights from the international aid and development sector. Int J Human Resour Manag. 2017;28(14):1960-1985. doi:10.1080/09585192.2015.1137617

45. Suthatorn P, Charoensukmongkol P. Cultural intelligence and airline cabin crews members' anxiety: the mediating roles of intercultural communication competence and service attentiveness. J Hum Resour Hosp Tour. 2018;17(4):423-444. doi:10.1080/15332845.2018.1449559

46. Ratasuk A, Charoensukmongkol P. Does cultural intelligence promote cross-cultural teams' knowledge sharing and innovation in the restaurant business? Asia Pac J Bus Administration. 2020;12 (2):183-203. doi:10.1108/APJBA-05-2019-0109

47. Charoensukmongkol $P$. The efficacy of cultural intelligence for adaptive selling behaviors in cross-cultural selling: the moderating effect of trait mindfulness. J Glob Mark. 2020;33(3):141-157. doi:10.1080/ 08911762.2019 .1654586

48. Kim K, Slocum JJW. Individual differences and expatriate assignment effectiveness: the case of US-based Korean expatriates. $J$ World Bus. 2008;43(1):109-126. doi:10.1016/j.jwb.2007.10.005

49. Pinto LH, Araújo RC. Social networks of Portuguese self-initiated expatriates. J Manag Dev. 2016;35(1):89-103. doi:10.1108/JMD-07-2014-0069

50. Barrick MR, Mount MK. The big five personality dimensions and job performance: a meta-analysis. Pers Psychol. 1991;44(1):1-26. doi:10.1111/j.1744-6570.1991.tb00688.x

51. Varma A, Pichler S, Budhwar P. The relationship between expatriate job level and host country national categorization: an investigation in the UK. Int J Hum Resour Manag. 2011;22(1):103-120. doi:10.1080/09585192.2011.538971

52. Jannesari M, Wang Z, Brown P, McCall J. Knowledge transfer between expatriate and host country nationals: the role of self-construal. Soc Behav. 2016;44(3):369-382. doi:10.2224/sbp.2016.44.3.369

53. Pillemer J, Rothbard NP. Friends without benefits: understanding the dark sides of workplace friendship. Acad Manag Rev. 2018;43 (4):635-660. doi:10.5465/amr.2016.0309

54. Sonesh SC, DeNisi AS. The categorization of expatriates and the support offered by host country nationals. J Glob Mobility. 2016;4 (1):18-43. doi:10.1108/JGM-09-2015-0036

55. Kaše R, Paauwe J, Zupan N. HR practices, interpersonal relations, and intrafirm knowledge transfer in knowledge-intensive firms: a social network perspective. Hum Resour Manag. 2009;48 (4):615-639. doi:10.1002/hrm.20301

56. Mezias JM, Scandura TA. A needs-driven approach to expatriate adjustment and career development: a multiple mentoring perspective. J Int Bus Stud. 2005;36(5):519-538. doi:10.1057/palgrave.jibs8400159

57. Gupta AK, Govindarajan V. Converting global presence into global competitive advantage. Acad Manag Perspect. 2001;15(2):45-56. doi:10.5465/ame.2001.4614881

58. Carraher SM, Sullivan SE, Crocitto MM. Mentoring across global boundaries: an empirical examination of home-and host-country mentors on expatriate career outcomes. J Int Bus Stud. 2008;39 (8):1310-1326. doi:10.1057/palgrave.jibs.8400407

59. Bauer TN, Bodner T, Erdogan B, Truxillo DM, Tucker JS. Newcomer adjustment during organizational socialization: a meta-analytic review of antecedents, outcomes, and methods. J Appl Psychol. 2007;92(3):707. doi:10.1037/0021-9010.92.3.707
60. Fu C, Hsu Y-S, Shaffer MA, Ren H. A longitudinal investigation of self-initiated expatriate organizational socialization. Pers Rev. 2017;46(2):182-204. doi:10.1108/PR-05-2015-0149

61. Cable DM, Parsons CK. Socialization tactics and person-organization fit. Pers Psychol. 2001;54(1):1-23. doi:10.1111/j.1744-6570.2001. tb00083.x

62. John OP, Srivastava S. The Big Five trait taxonomy: history, measurement, and theoretical perspectives. Handb Pers. 1999;2 (1999):102-138.

63. McAllister DJ. Affect-and cognition-based trust as foundations for interpersonal cooperation in organizations. Acad Manag J. 1995;38 (1):24-59. doi:10.5465/256727

64. Podsakoff PM, MacKenzie SB, Podsakoff NP. Sources of method bias in social science research and recommendations on how to control it. Ann Rev Psychol. 2012;63(1):539-569. doi:10.1146/ annurev-psych-120710-100452

65. Baron RM, Kenny DA. The moderator-mediator variable distinction in social psychological research: conceptual, strategic, and statistical considerations. J Pers Soc Psychol. 1986;51(6):1173-1182. doi:10.1037/0022-3514.51.6.1173

66. Hayes AF, Matthes J. Computational procedures for probing interactions in OLS and logistic regression: SPSS and SAS implementations. Behav Res Methods. 2009;41(3):924-936. doi:10.3758/BRM.41.3.924

67. Preacher KJ, Rucker DD, Hayes AF. Addressing moderated mediation hypotheses: theory, methods, and prescriptions. Multivariate Behav Res. 2007;42(1):185-227. doi:10.1080/00273170701341316

68. Hogan J, Holland B. Using theory to evaluate personality and job-performance relations: a socioanalytic perspective. $J \mathrm{Appl}$ Psychol. 2003;88(1):100. doi:10.1037/0021-9010.88.1.100

69. Shaffer MA, Harrison DA, Gregersen H, Black JS, Ferzandi LA. You can take it with you: individual differences and expatriate effectiveness. J Appl Psychol. 2006;91(1):109-125. doi:10.1037/ 0021-9010.91.1.109

70. Varma A, Budhwar P, Katou A, Matthew J. Interpersonal affect and host country national support of expatriates. J Glob Mobility. 2016;4 (4):476-495. doi:10.1108/JGM-02-2016-0007

71. Chen Y-P, Shaffer MA. The influences of perceived organizational support and motivation on self-initiated expatriates' organizational and community embeddedness. J World Bus. 2017;52(2):197-208. doi:10.1016/j.jwb.2016.12.001

72. Athota VS, Budhwar P, Malik A. Influence of personality traits and moral values on employee well-being, resilience and performance: a cross-national study. Appl Psychol. 2020;69(3):653-685. doi:10.1111/apps. 12198

73. Jannesari MT, Sullivan SE. Leaving on a jet plane? The effect of challenge-hindrance stressors, emotional resilience and cultural novelty on self-initiated expatriates' decision to exit China. Per Rev. 2021; ahead-of-print(ahead-of-print). doi:10.1108/PR-05-2020-0362

74. Singh SK, Edward Pereira V, Mellahi K, Collings DG. Host country nationals characteristics and willingness to help self-initiated expatriates in the UAE. Int J Hum Resour Manag. 2019;1-24. doi:10.1080/ 09585192.2018 .1547778

75. Hofstede G. Culture's Consequences: National Differences in Thinking and Organizing. Beverly Hills, CA: Sage Publications; 1980.

76. Fee A. How host-country nationals manage the demands of hosting expatriates: an exploratory field study. J Glob Mobility. 2020;8 (1):25-54. doi:10.1108/JGM-09-2019-0045

77. Schuster T, Ambrosius J, Bader B. Mentoring in international assignments: a personality traits perspective. Empl Relat. 2017;39 (7):1100-1130. doi:10.1108/ER-09-2016-0180 


\section{Publish your work in this journal}

Psychology Research and Behavior Management is an international, peer-reviewed, open access journal focusing on the science of psychology and its application in behavior management to develop improved outcomes in the clinical, educational, sports and business arenas. Specific topics covered in the journal include: Neuroscience, memory and decision making; Behavior modification and management; Clinical applications; Business and sports performance management; Social and developmental studies; Animal studies. The manuscript management system is completely online and includes a very quick and fair peer-review system, which is all easy to use. Visit http://www. dovepress.com/testimonials.php to read real quotes from published authors.

Submit your manuscript here: https://www.dovepress.com/psychology-research-and-behavior-management-journal 